\section{Premarital Sex in Costa Rica: Incidence, Trends and Determinants}

\author{
"The adjusted risk [of premarital sex] is seven times higher \\ for women who are engaged to marry compared with those \\ who are not. Premarital coital activity among Costa Rican \\ teenagers is thus driven in part by marriage at a young age."
}

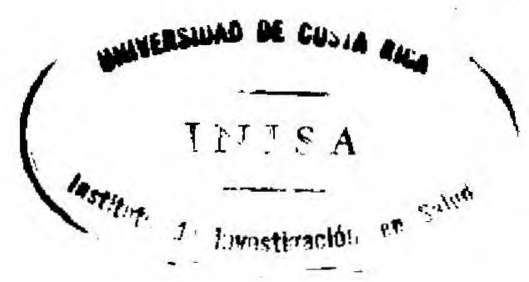

\section{By Luis Rosero-Bixby}

\section{Summary}

A hazards model using retrospective data from a national sample of Costa Rican women aged 15-24 interviewed in 1986 indicates that every year approximately 10 vercent of women aged 17-19-the peak

- ages for the initiation of premarital sexual activity - become sexually active. The cumulative proportion of women who have had premarital sex by their 20th birthday is 38 percent. The data fail to support the popular belief that premarital sexual activity has increased among younger cohorts: The younger cohorts of women tended to have a lower risk of premarital sexual activity than the older cohorts. Education reduces the risk of premarital sex, whereas being engaged to marry increases this risk sharply. Women in communities with large proportions of consensual unions tend to have an increased likelihood of premarital sex, and the restraining effects of education tend to be weakened.

\section{Introduction}

The incidence of premarital sex is probaly high in many Latin American countries. It is poorly documented, however, because of the lack of data and the use of inadequate indicators. Nevertheless, high regional levels of adolescent fertility, outof-wedlock births and consensual unions suggest substantial coital activity before or

Luis Rosero-Bixby is a professor at the Instituto de Investigaciones en Salud, Universidad de Costa Rica. The Costa Rican Demographic Association collected the data on which this article is based as part of the National Fertility and Health Survey, with the assis. tance of the Centers for Disease Control. Doris Sosa was the survey director and the United States Agency for International Development (USAID) funded the survey. The opinions expressed do not necessarily reflect those of USAID. Mark Oberie, Leo Morris and William Mason made useful suggestions to improve the manuscript. A version of this article was distributed at the International Conference on Adolescent Fertility in Latin America and the Caribbean, Oaxaca, Mexico, November 1989. outside of legal marriage. This article uses a national sample of Costa Rican women to estimate current incidence and recent trends of premarital sexual activity, with the hypothesis that premarital sexual activity is increasing. It also addresses the question of how individual and contextual characteristics determine the likelihood of engaging in premarital sex. Sexual activity within marriage or consensual union, even if it occurs at a young age, is not within the scope of this study. The findings should help direct the efforts of family planning programs and other interventions to prevent pregnancy and sexually transmitted diseases among adolescents.

Two types of forces influence the initiation of coital activity before marriage-the microlevel, or the individual characteristics of an adolescent, and the macrolevel, the social context in which she lives including the marriage norms and sanctions on sex outside of marriage. The microlevel variables in this analysis are the adolescent's level of education and whether she is engaged to marry. The macrolevel variable considered here is the looseness of community social norms regarding marriage, as measured by the prevalence of consensual unions.

Figure 1 (page 26) depicts the model of causal relationships used in the present analysis. To test the hypothesis that premarital sex has recently increased, the model includes two cohort effects-an indirect effect operating through education and engagement to marry, and a direct effect, represented by the arrow connecting the cohort and premarital sex variables.

Educational attainment, as an indicator of socioeconomic status, modernity and alternatives for young women other than dating and marriage, can affect the probability of premarital sex. In Costa Rica, modernity and a high socioeconomic status are thought to be conducive to premarital sexual activity. In addition, educa- tion can act indirectly by postponing engagements to marry, the other microlevel determinants in the model. On the other hand, the content of school curricula and the values transmitted by formal education can also influence the initiation of sexual activity by transferring the prevailing sexual and marital values in Costa Rican society, which strongly condemn premarital intercourse.

The contextual variable in the model is thought to be positively associated with premarital sex: Communities with traditionally high levels of consensual unions probably have a high incidence of premarital sex. In addition, the microlevel effects probably change in different contexts. Figure 1 portrays this interactive effect with an arrow from the macro determinant modifying the other three causal links to premarital sex. The model posits no causeeffect relationships between social marital norms and educational attainment or cohort.

An indirect effect of social marital norms working through engagement is also depicted in the diagram: In cultures where the institution of marriage is valued highly, engagements are entered into earlier and last longer, and the risk of premarital intercourse probably increases with the duration of the engagement. Identifying this intervening effect is important because if most, or a substantial part, of premarital sexual activity occurs among engaged couples, then the causal relationship between engagement and early age at marriage would proceed, in theory, from marriage to premarital sex rather than the other way around.

Since young women choose neither the community they live in nor the year they are born, it seems appropriate to treat social marital norms and age-cohort as exogenous variables. Accepting causality between education and premarital sex on the one hand, and engagement and pre- 
Figure 1. Causal model depicting the determinants of the initiation of premarttal sex, Coste Fica, 1986

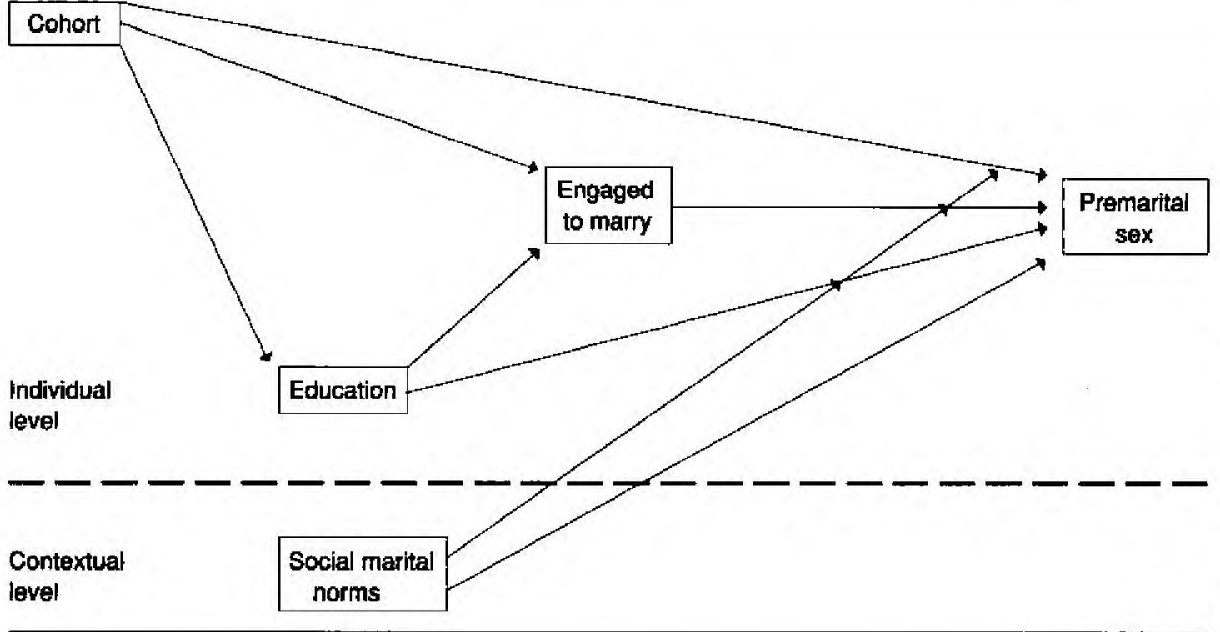

marital sex on the other, assumes the former variables precede the latter. The required time sequence was assured by making education and engagement timedependent variables; that is, they were computed at the beginning of each month of exposure.

\section{Data and Methods}

Measurement of the incidence of premarital sex can be difficult. An indicator frequently used in the literature is the proportion of women who have ever had premarital intercourse. ${ }^{1}$ This proportion can be misleading because it actually measures both the risk (per unit of time) of initiating sexual activity before marriage and the length of exposure to the risk. With all other factors held constant, the proportion who have ever had premarital sex should increase with age and with older age at marriage because of the increased duration of exposure. In other words, the

"This classification error may bias the true effect of the exposure either upwards or downwards. The bias, however, is acceptable if the effect of engagement is substantial and the amount of time that adolescents spend engaged is short. Let's assume, for example, that 10 percent of the years from ages 12-19 is spent in engagement; only half of the engagement period is correctly classified by the definition of three months before marriage; and the relative risk of premarital sex is $\mathbf{8 . 0}$ for the five percent exposure period that has been correctly classified. If the relative risk for the misclassified exposure were identical to the correctly classified period, the observed relative risk would be $5.8 \mathrm{com}$ pared with an actual value of 8.0 . If, by contrast, the relative risk for the misclassified exposure were only 2.0 , the observed relative risk would be 7.6 , compared with a true value of 5.0. These two examples represent extreme situations and, therefore, the error is probably in the range of plus-or-minus three points, for a true relative risk ranging between 5.0 and 8.0 . date of the survey interview truncates the exposure in younger women while marriage truncates the exposure in women who married earlier than the date of interview. Measures of the risk of premarital sexual activity should be independent of these two censoring effects, particularly when the risks between populations or across time are being compared. Life-table methods, also called hazards models, can efficiently handle these types of censoring effects and effectively incorporate timevarying covariates as well. ${ }^{2}$

This article describes the results of a proportional hazards model, or Cox's model, that simultaneously examines the effects of several variables on the risk of premarital sex. The major assumption of Cox's model is that the relative risk is constant at each duration or age, which is not to say that the risk itself is constant over time. Actually, the risk, or hazard, can be any function of time, as long as this function is the same in all individuals or groups. Moreover, the assumption of a constant relative risk over time is not a crucial feature of the model because the hazards cease to be proportional as soon as time-dependent explanatory variables are introduced. ${ }^{3}$ Cox's model compares hazards of individuals with identical ages or durations to estimate relative risks and thus it implicitly controls for the effect of different age structures.

The analysis utilizes data from the 1986 Fertility and Health Survey, a nationally representative survey conducted by the Costa Rican Demographic Association in collaboration with the U.S. Centers for Disease Control. ${ }^{4}$ The survey asked 1,379 women from 15 to 24 years of age whether and when they had first had premarital intercourse. This figure shrank to 1,358 women after incomplete or inconsistent observations were excluded. Consensual unions were considered in the analysis as marriages. Subjects were grouped into three age-cohorts according to the year of the woman's 15th birthday-1976-1979, 1980-1982 and 1983-1985; these three agecohorts correspond to women who were approximately aged $21-24,18-20$ and $15-17$, respectively, at the date of the interview. The number of years of education completed at each month of the young woman's life, starting at age 12, was estimated by combining information on the years of education and age at the time of the interview, tusing Costa Rican standards of correspondence between age and educational level.

The dichotomous, time-dependent variable "engaged or not" was defined mont] by month. Since the survey did not ask the date of engagement, this date was set at three months before the legal marriage; women who were single or in consensual unions were considered to have never been engaged. The major limitation of these assumptions is that the periods of engagement not resulting in legal marriages are missed.*

The contextual variable "looseness of marriage norms," was measured by the proportion of couples in consensual union in each canton (or county), which was obtained by the 1973 census. The use of these relatively old data was deliberate, since the analysis considers the social context of the woman's childhood rather than that of

Table 1. Among women aged 15-24 in 1986, estimated number of woman-years of expc sure to the risk of premarital sex, annual rate of Initiation of premarttal sex and cumulative probability (and standard errors), by age, Costa Alca, 1986

\begin{tabular}{lrrr}
\hline Age & $\begin{array}{l}\text { Woman- } \\
\text { years of } \\
\text { exposure }\end{array}$ & \multicolumn{1}{l}{$\begin{array}{l}\text { Annual } \\
\text { rate }\end{array}$} & \multicolumn{1}{c}{$\begin{array}{l}\text { Cumulative } \\
\text { probability }\end{array}$} \\
\hline 12 & $1,354.0$ & $0.7(0.2)$ & na \\
13 & $1,339.0$ & $1.7(0.4)$ & $0.7(0.2)$ \\
14 & $1,292.5$ & $3.2(0.5)$ & $2.3(0.4)$ \\
15 & $1,161.0$ & $5.8(0.7)$ & $5.4(0.6)$ \\
16 & 949.0 & $5.5(0.7)$ & $10.7(0.9)$ \\
17 & 738.5 & $9.4(1.2)$ & $15.5(1.0)$ \\
18 & 532.0 & $9.8(1.4)$ & $23.4(1.3)$ \\
19 & 372.5 & $11.4(1.8)$ & $30.6(1.5)$ \\
20 & 244.0 & $8.2(1.8)$ & $38.0(1.8)$ \\
21 & 156.5 & $5.9(1.9)$ & $42.9(1.9)$ \\
22 & 86.5 & $8.4(3.2)$ & $46.2(2.1)$ \\
23 & 37.0 & $5.5(4.0)$ & $50.5(2.5)$ \\
24 & 9.5 & na & $53.2(3.0)$ \\
\hline
\end{tabular}

Note: na=not applicable. Source: Data tape from the Encuesta Nacional de Fecundidad y Salud, Costa Rica, 1986, Asociación Demogrática Costarricense. 
her current situation. The 1986 survey questionnaire asked about the respondent's main residence only during the five years preceding the survey. Less than 15 percent of women probably moved before this five year period and thus the great majority spent most of their childhood in the canton recorded in the survey. The proportion in consensual union, as well as years of education, were included as continuous variables in the model.

A separate life-table estimated the risk of premarital sex by age. Cox's models with time-dependent covariates were used to estimate the proposed micro and macro effects.* The "survival" or "failure" time variable for these analyses-that is, the length of time between the beginning of the observation and the target event-was counted in months, starting at age 12. Censoring occurred at marriage for entry to a consensual union) or three months before the interview, whichever came first. The BMDP statistical software package was used to compute the restults. ${ }^{5}$

\section{Results}

How common is premarital sex in Costa Rica? Twenty-eight percent of women aged 15-24 stated that they had had premarital intercourse. This percentage, though indicative of considerable sexual activity before marriage, is a crude measure because it is affected by the censoring effects previously pointed out. Table 1 presents the more meaningful life-table analysis and shows that the annual rate, or risk, of initiating premarital sexual activity reaches a peak at ages 17 to 19 . At its highest value, the risk is 9-11 percent per year. The rate of initiation of premarital interfourse is lower before age 17: The risks are whe percent at age 12 and six percent at ages 15-16. The life-table suggests a decline in the risk after age 19, but the estimates are too imprecise (the standard errors are large) to draw definitive conclusions.

The last column in Table 1 shows the proportion of unmarried women who have had sex before the specified age. This cumulative probability of having premarital sex increases monotonically with age. Twenty-three percent of young women have engaged in premarital sex before their 18 th birthday, and 38 percent by their 20 th birthday, a proportion that rises to 53 percent at age 24.

To what extent is premarital sex associated with each of the other variables? As expected, the crude percentage that have had premarital sex is higher among the older cohorts: Among those aged 21-24 at
Table 2. Among cohorts of 15-24-year-old women, annual rates of initiation of premarital sex (and standard errors), by ago; and cumulative probability by 18 th birthday

\begin{tabular}{|c|c|c|c|}
\hline \multirow[t]{2}{*}{ Age } & \multicolumn{3}{|l|}{ Cohort ${ }^{*}$} \\
\hline & $\begin{array}{l}1976-1979 \\
(\mathrm{~N}=490)\end{array}$ & $\begin{array}{l}1980-1982 \\
(\mathrm{~N}=420)\end{array}$ & $\begin{array}{l}1983-1985 \\
(\mathrm{~N}=448)\end{array}$ \\
\hline 12 & $0.4(0.2)$ & $0.5\{0.4\}$ & $1.1(0.5)$ \\
\hline 13 & $1.7(0.6)$ & $2.2(0.7)$ & $1.1(0.5)$ \\
\hline 14 & $2.4(0.7)$ & $4.6(1.1)$ & $2.9(0.8)$ \\
\hline 15 & $6.0(1.2)$ & $7.1(1.4)$ & $4.0(1.1)$ \\
\hline 16 & $5.5(1.1)$ & $6.6(1.4)$ & $3.7(1.4)$ \\
\hline 17 & $10.8(1.8)$ & $9.5(1.8)$ & $6.0(3.0)$ \\
\hline 18 & $10.4(1.9)$ & $9.3(2.0)$ & $t$ \\
\hline 19 & $10.7(2.0)$ & $12.7(3.4)$ & $t$ \\
\hline 20 & $6.9(1.8)$ & $\dagger$ & $t$ \\
\hline $\begin{array}{c}\text { Cumulative } \\
\text { probabilit } \\
\text { by 18th } \\
\text { birthday }\end{array}$ & $23.5(2.0)$ & $26.2(2.2)$ & $17.1(3.0)$ \\
\hline
\end{tabular}

"Cohort defined by year of the respondent's 15 th birthday.

t Less than 100 exposed individuals.

the time of the survey, 40 percent have had premarital sex, compared with 34 percent of those in the middle cohort (ages 18-20 at the interview) and 20 percent of those in the youngest cohort (ages 15-17 at the interview). The association between agecohort and premarital sex is substantial, but it cannot be concluded that the likelihood of premarital sex is declining in younger cohorts; the association is undoubtedly an artifact of the truncated exposure among the younger cohorts.

Marital status and the probability of premarital sex appear to be strongly related. Among ever-married women, 53 percent had had premarital sex, compared with 13 percent among single women. Once again, uncontrolled exposure to risk is a problem: Single women are probably younger and thus have been exposed for a shorter period of time, and married women have a censored exposure because of their marriage. It is not clear whether the higher percentage of premarital sex among married women is attributable to an increased risk of premarital sex during engagements, some other factor associated with not having sex while single, or more openness among married women in reporting premarital sex.

A clear negative association also exists between education and premarital sex. The proportion of college-educated women who have had premarital sex is half that of women with only an elementary school education (17 percent vs. 34 percent). In addition, 25 percent of those who had a secondary school education had initiated sexual activity before marriage. However, since younger age at interview and earlier age at marriage (shorter exposure) are associated with less education, censoring effects once again influence the comparison. Moreover, given that the measure of education corresponds to the time of the interview rather than to the period of exposure, one may argue that the association is spurious or even that low educational level is a consequence rather than a cause of premarital sexual activity; that is, early sexual activity may lead to dropping out of school.

The results indicate a positive association between a tradition of consensual unions in the community and the likelihood of premarital sex. In cantons where less than 10 percent of couples were in a consensual union in 1973, 24 percent of the women surveyed in 1986 had had premarital intercourse. The corresponding proportions of those who initiated premarital sex in cantons with $10-19$ percent and $\geq 20$ percent of couples in consensual unions were 28 percent and 40 percent, respectively. However, this association could be affected by the tendency toward lower educational attainment and early marriage in communities with high proportions of consensual unions.

The associations examined so far, although they suggest that levels of premarital sex are affected by early marriage, education and social norms, are hardly conclusive. The proportion of women who have had premarital sex is biased by differences in the length of exposure time or by censoring effects. A discrete life-table analysis is a straightforward approach to controlling for the censoring effects. Table 2 compares the life-table, age-specific rates of premarital sexual activity among different age-cohorts. Women in the 1980-1982 cohort have slightly higher rates of sexual initiation than the 1976-1979 cohort, except at ages 17 and 18 . Women in the youngest cohort (1983-1985) have lower rates than either of the older cohorts except at age 12 . However, the large standard errors of these annual rates prevent

"William Mason distinguishes between two approaches of estimating macro effects in multilevel analyses-the fixed effect approach, which assumes no disturbances to the macro effects and the stochastic-parameter approach, which assumes the existence of macro disturbances independent of micro errors. Since the currently available software used to estimate Cox's models allows for only one type of disturbance, the estimates in the present article use the fixed-effect approach. In the empirical example presented by Mason to compare the two approaches for logistic regression, the results were virtually identical. (See W. M. Mason, "Addendum to Manual DX: The Methodology of Measuring the Impact of Family Planning Programmes on Fertility," Population Studies, No. 66, United Nations, 1986, pp. 24-31). 


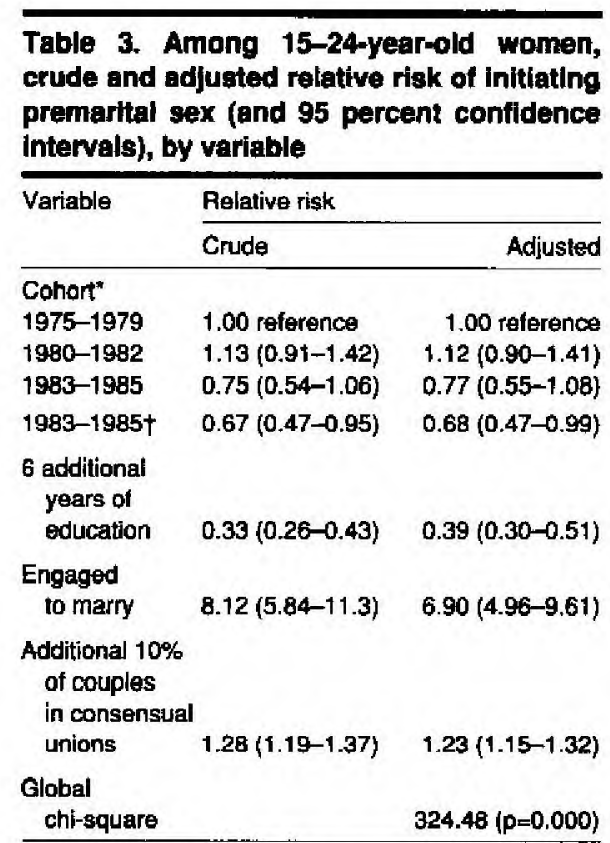

"Cohort defined by year of the respondent's 15th birthday.

tCalculated with the 1980-1982 cohort as the reference group.

drawing conclusions about the existence of trends. The cumulative probability of having had premarital sex by age 18 for the 1976-1979, 1980-1982 and 1983-1985 cohorts is 24 percent, 26 percent and 17 percent, respectively. Although the slight increase between the two older cohorts is not statistically significant, the decline for the youngest cohort is. If there is a trend, then it is toward declining rates of premarital sexual activity among younger women.

The use of Cox's model conveniently summarizes comparisons of age-specific rates from discrete life-tables. The model also facilitates multivariate analyses, which are severely limited by the sample size in discrete life-tables, and considers the lifetime variations in conditions such as education and engagement status. Table 3 presents two series of relative risks estimated with Cox's model, namely "crude"

"The table also shows two pieces of information for statistical inference- the 95 percent confidence interval for the estimated relative risks, and the global chisquare with their probabilities. Confidence intervals whose range includes the value of 1.0 indicate statistically nonsignificant effects. The global chi-square statistic, and its p-value, test the hypothesis that all regression coefficients are identically zero, which is a way of testing the fit of the model as a whole.

tThe chj-square test was used to evaluate the statistcal significance of the two-term interactions between the contextual variable and each of the individual variables. All two-term interactions implicit in Table 4 were statistically significant at $p=, 05$. and "adjusted," for the four explanatory variables under study. The crude relative risks describe bivariate associations estimated with separate hazards models for each explanatory variable. The adjusted relative risks, which show the net or direct effect of each variable on the rate of premarital sex, come from a multivariate model that includes all the explanatory variables.

The differences between the crude and adjusted relative risks, if any, indicate the importance of indirect and shared effects." The fact that the differences are trivial suggests that the indirect effects are minor, and it is not necessary to study the two series separateiy. Therefore, the analysis focuses on the adjusted series of relative risks only.

The relative risks by cohort confirm the results from the discrete life-table analysis and refute the popular perception that sexual activity among young people has recently increased. The adjusted risk of initiating intercourse before marriage is 12 percent higher among the 1980-1982 cohort than among the 1976-1979 cohort, but this slightly elevated risk is not statistically significant. Young women in the 1983-1985 cohort are 23 percent less likely to initiate premarital sexual activity than those in the 1976-1979 cohort but a full 32 percent less likely to do so than those in the $1980-1982$ cohort, a statistically significant difference.

The preventive effect of education on early premarital sex is clear from the results of the proportional hazards model in Table 3. Holding all other variables constant, each six additional years of education reduces the risk of initiating coital activity before marriage by 61 percent. As expected, the period of engagement is particularly risky for the initiation of coital activity. The adjusted risk is seven times higher for women who are engaged to marry compared with those who are not. Premarital coital activity among Costa Rican teenagers is thus driven in part by marriage at a young age.

The results in Table 3 of the effect of the proportion of consensual unions in the community are consistent with the hypothesis that premarital sex is partly determined by contextual, or macro, characteristics. Young women who live in cantons that presumably have loose social noms of marriage, as indicated by traditionally high proportions of consensual unions, are more likely to initiate coital activity before marriage or entry into a union. For each 10 percentage points in the proportion of all unions in the canton that
Table 4. Among 15-24-year-old women, adjusted relative risk of Initlating premarital sex (and 95 percent confidence intervals), by the percentage of consensual unlons in the community, according to vartable

\begin{tabular}{|c|c|c|}
\hline \multirow[t]{2}{*}{ Varlable } & \multicolumn{2}{|l|}{ Consensual unions } \\
\hline & $\begin{array}{l}<20 \% \\
(N=1,042)\end{array}$ & $\begin{array}{l}\geq 20 \% \\
(N=316)\end{array}$ \\
\hline \multicolumn{3}{|l|}{ Cohort' } \\
\hline $976-1979$ & 1.00 reference & 1.00 reference \\
\hline 1980-1982 & $1.03(0.79-1.36)$ & $1.28(0.86-1.89)$ \\
\hline 1983-1985 & $0.63(0.41-0.98)$ & $1.05(0.61-1.81)$ \\
\hline $1983-1985 \dagger$ & $0.61(0.38-0.97)$ & $0.82(0.46-1.45)$ \\
\hline $\begin{array}{l}6 \text { additional } \\
\text { years of } \\
\text { oducation }\end{array}$ & $0.33(0.24-0.45)$ & $0.51(0.32-0.82)$ \\
\hline $\begin{array}{l}\text { Engaged } \\
\text { to marry }\end{array}$ & $9.01(6.29-12.9)$ & $2.80(1.96-6.96)$ \\
\hline $\begin{array}{l}\text { Global } \\
\text { chi-square }\end{array}$ & $304.79(p=0.000)$ & $15.43(p=0.004)$ \\
\hline
\end{tabular}

"Cohort defined by year of the respondent's 15 th birth day.

tCalculated with the 1980-1982 cohort as the reference group.

are consensual, the risk of premarital sex increases by 23 percent, net of the effect of the other explanatory variables. In the extreme case of cantons where, for example, half of all couples are in consensual unions, this risk would be three times higher than in cantons where legal marriage is universal (i.e., 1.23 to the power of five, yielding a relative risk of 2.8 ).

With the existence of a contextual effect confirmed, the final step in the analysis is to determine if the contextual variable also influences the microlevel effects. Table 4 compares the microlevel effects on the initiation of premarital sex among cantons with a low prevalence of consensual uny ions and those with a high prevalence.t The table shows that the proposed moderator effect of the social context indeed exists. The decline in premarital sexual activity among the 1983-1985 cohort occurs only in contexts where consensual unions are rare. Moreover, the microlevel effects of education and engagement are substantially reduced-although they are still significant-in cantons where consensual unions are common. In these cantons, each six additional years of education reduces the risk of initiating premarital sex by 49 percent, and during periods of engagement, the risk increases nearly threefold (relative risk of 2.8). By contrast, in cantons with low proportions of consensual unions, each six additional years of education reduces the risk of premarital sex by 67 percent, and being engaged increases this risk by a factor of nine. 


\section{Conclusions}

The evidence from the analysis confirms that the incidence of premarital sex in Costa Rica is high. At the peak ages of 17-19, the annual risk of initiating premarital sexual activity is about 10 percent; the cumulative proportion who have had premarital sex by age 20 is 38 percent. However, the data refute the popular belief that the incidence of premarital sex has increased among younger cohorts: Women in the youngest cohort - those who turned 15 in 1983-1985-have lower risks of initiating premarital sex than women in the two older cohorts. Although this difference is statistically significant, it is probably premature to conclude that a downward trend has started. The youngest cohort was observed only until their 18 th birthday, and the trend may reverse itself after that age. The apparent decline may lso reflect less openness among younger respondents in reporting premarital sexual experience.

The results of the analysis confirm the proposed microlevel effects of education and engagement: Increased education reduces the risk of premarital sex, and this risk rises sharply during periods of engagement. The results also confirm the macrolevel influence of the prevailing marriage norms, as well as the interaction of this variable with the microlevel variables: In cantons with loose marriage norms, the likelihood of premarital sex is high, and the microlevel effects of education are weakened.

The analysis demonstrates the critical role of education and social context. It also suggests that the relationship between early marriage and premarital sex is more yomplex than it appears. It would be misceading to speak of premarital sex as the cause and early marriage as the effect. In some circumstances the contrary is true: Premarital intercourse is often considered less of a sin once a formal engagement has been entered into and much of the premarital sexual activity in Latin America probably takes place during this period of engagement. Adolescent women initiate sexual activity at a young age because they engage to marry at a young age. As a policy implication, the results of the analysis indicate the importance of targeting prevention programs in adolescent pregnancy and sexually transmitted diseases to single adolescents with low educational attainment and to those living in communities with traditionally high proportions of consensual unions.

\section{References}

1. L. Morris, "Young Adults in Latin America and the Caribbean: Their Sexual Experience and Contraceptive Use," International Family Planning Perspectives, 14:153, 1988.

2. P. D. Allison, Event History Analysis: Regression for Longifudinal Event Data, Sage Publications, Beverly Hills, Calif., 1984.

3. Ibid.

4. Data tape from the Encuesta Nacional de Fecundidad y Salud, Costa Rica, 1986, Asociación Demografica Costarricense; and M. W. Oberle et al., "Contraceptive Use and Fertility in Costa Rica, 1986," Infernational Family Planning Perspectives, 14:103, 1988.

5. W. J. Dixon, ed., BMDP Statistical Softuare, University of California Press, Berkeley, Calif,, 1985.

\section{Resumen}

Según un modelo de riesgo en que se utilizaron datos retrospectivos de una muestra nacional de mujeres costarricenses de entre 15 y 24 años entrevistadas en 1986, cada año aproximadamente el 10 por ciento de las mujeres de entre 17 y 19 años-la edad más proclioe a la iniciación sexual prematrimonial-comienzan su vida sexual actioa. La proporción acumulada de mujeres que han tenido relaciones sexuales antes del matrimonio a los 20 años es del 38 por ciento. Estos datos no corroboran la creencia popular de que la actividad sexual antes del matrimonio ha aumentado entre las cohortes más jóvenes, pues las de menor edad tendieron a registrar menos riesgo de actividad sexual prematrimonial que las cohortes mayores. La educación reduce el riesgo de sexo prematrimonial, mientras que estar comprometida para casarse lo aumenta marcadamente. En las comunidades con grandes porcentajes de uniones consensuales la probabilidad de sexo prematrimonial es mayor, tendiendo a atenuarse los efectos restrictioos de la educacion.

\section{Resumẹ}

Un modele de risques ayant recours aे des données rétrospectives provenant d'un échantillon national de Costa-riciennes âgées de 15 à 24 ans, interviewées en 1986, indique que, chaque année, environ 10 pour cent des femmes âgées de 17 a 19 ans (äges auxquels debutent principalement les activités sexuelles prémaritales), deviennent sexuellement actives. La proportion cumulative de femmes ayant eu des rapports sexuels prémaritaux avant leur $20 \mathrm{~m}$ e anniversaire de naissance est de 38 pour cent. Les données ne confirment pas la croyance populaire suivant laquelle les rapports sexuels prémaritaux ont augmenté parmi les cohortes plus jeunes: règle générale, le risque d'actiotités sexuelles prémaritales était plus bas chez les cohortes de femmes les plus jeunes par rapport aux cohortes de femmes plus agées. L'instruction réduit le risque d'activités sexuelles prémaritales, ce même risque étant de beaucoup accru chez les fiancées. Dans les communautés où les unions consensuelles sont répandues, les femmes sont generalement plus susceptibles d'avoir des rapports sexuels prémaritaux, et l'instruction tende davoir un effet moins fort. 

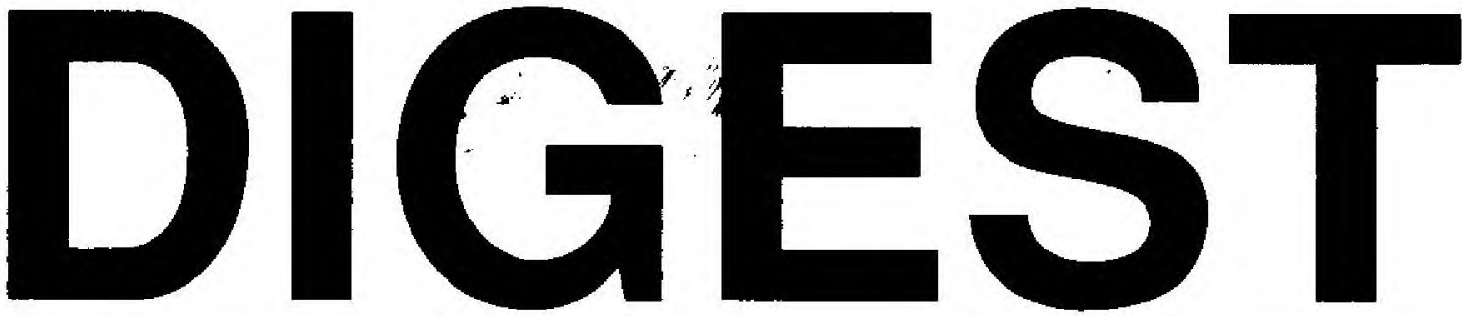

\section{Trinidad and Tobago: Users of Reversible Methods Prefer Pill or Condoms over Hormonal injectables}

The pill is the most popular method among women in Trinidad and Tobago. However, although most women who have practiced contraception have used oral contraceptives, only about one-fourth of current users are doing so. The condom, used by just over one-fifth of current contraceptive users, is the next most popular method. Female sterilization, used by 16 percent of current users, is the most popular method among those aged 35-49. Injectables are not popular among women in Trinidad and Tobago; the vast majority of women who try them do not continue using them. These are some of the highlights of a 1990 follow-up analysis of data from the 1987 Trinidad and Tobago Demographic and Health Survey (DHS). '

Trinidad and Tobago is a republic made up of two main islands and several smaller islands in the Caribbean. About 80 percent of the population is of Indian or African ethnicity, in approximately equal proportions. The republic's Family Planning Association provides a variety of contraceptives at little or no cost.

\section{Contraceptive Use}

In the 1987 DHS, 63 percent of all respondents aged 15-49 and 82 percent of those ever in a union* said they had practiced contraception at some point in the past. Those aged $25-29$ are most likely to have ever used contraceptives (86 percent), while those aged 15-19 and 45-49 are least likely to have used them ( 69 percent and 73 percent, respectively). Although there is some variation in ever-use according to education, residence, ethnicity, current union status and religion, the majority of

"Women are said to be "in a union" if they are legally married and living together, in a common-law union (i.e., living with a sexual partner) or in a visiting union (i.e., having regular sexual relations with one partner). All data given here on ever-use or current use of contraceptives are for women ever in a union or currently in a umion, respectively. women in all the subgroups have used contraceptives.

Sixty-seven percent of women who have ever practiced contraception have tried the pill, 58 percent have used the condom and 36 percent withdrawal. The pill is the method most likely to have been tried by ever-users between ages 20 and 49 . Women 15-19, however, are more likely to have used withdrawal or the condom (58 percent and 53 percent, respectively) than the pill (42 percent). About 10 percent of everusers are protected by female sterilization; in general, the proportion sterilized increases with age, with almost one-quarter of women 45-49 having undergone sterilization.

The pill is the most popular method among ever-users in each educational, residential and ethnic subgroup. The popularity of other methods varies somewhat, however: RuraI women and women with a primary education or less are more likely than their urban and more educated counterparts to have been sterilized and are less likely to have ever used periodic abstinence. Urban women are more likely than rural women to have ever used the IUD. In addition, a greater proportion of non-Indian than Indian women have ever used the IUD, periodic abstinence and vaginal methods.

In the 1987 DHS, 53 percent of women currently in a union reported that they were practicing contraception at that time. Patterns of current use according to subgroup are, in general, similar to those of ever-use. However, while non-Indians are more likely than Indians to have ever practiced contraception ( 87 percent vs. 76 percent), they are less likely to currently be doing so ( 50 percent vs. 57 percent). Similarly, ever-use is greater among Roman Catholics ( 85 percent) than among Hindus or other non-Christians ( 79 percent and 83 percent, respectively), but current use is greater among Hindus and other non-
Christians (about 57 percent of each group) than among Catholics (54 percent).

Among current users aged 15-34, the pill is the most commonly used method (ranging from 24 percent to 41 percent). Among older women, however, female sterilization is the most popular method: More than one-quarter of women aged 35-39 and over half of those aged 45-49 are sterilized. Female sterilization is, overall, the third most popular method among current users (16 percent), following oral contraceptives (26 percent) and the condom (22 percent).

Thirty percent of current users aged 15-19 use withdrawal or periodic abstinence. The author of the report finds this proportion "appallingly high" in light of the accessibility of more effective methods. She also suggests that the 1987 finding that there is a high degree of knowledge about contraceptives in this agegroup ( 94 percent had general knowledge and 93 percent knew about modern methods) "should be suspect."

The pill is not favored by all subgroups of current users as overwhelmingly as by ever-users. For instance, rural women are about as likely to use the condom ( 25 percent) as the pill (24 percent). In addition, legally married women and Hindu women are more likely to use the condom (27 percent and 28 percent, respectively) than they are to use the pill (21 percent and 24 percent, respectively).

The 1987 DHS asked all women who were not currently practicing contraception if they intended do so in the future. Of the 2,384 who were not using contraceptives at the time of the survey, 35 percent said they intended to use them in the future. Women aged 15-34 are more likely than those aged 35-49 to intend future use (34-51 percent vs. $3-22$ percent). In addition, women with a secondary or greater education are more likely than those with a primary or less education to intend to 